\title{
Covid-19 x Cães e Gatos
}

\author{
Covid-19 x Dogs and Cats
}

Andressa de Melo Jardim*a; Elis Lorenzettia; Fabíola Cristine de Almeida Rego Grecco ${ }^{\mathrm{a}}$

aUnopar, Programa de Pós-Graduação Stricto Sensu em Saúde e Produção Animal. PR, Brasil.

*E-mail: andressa.melo1982@gmail.com

\begin{abstract}
Resumo
Nos últimos meses, em todo o mundo, tem-se falado muito em COVID-19, uma doença que ocasionou um surto na China e rapidamente espalhou-se pelo mundo, tendo se transformado em uma pandemia. Em meio a esse cenário, dentre diversas questões, foi levantada uma dúvida em relação à possibilidade de infecção e posterior transmissão dessa doença viral dos animais de companhia, mais especificamente, cães e gatos, para indivíduos destas mesmas espécies ou até mesmo para os humanos. Este trabalho tem por objetivo elucidar, de forma clara e objetiva, o que é a COVID-19, sua origem e comportamento do agente viral responsável pela doença, com o intuito de disseminar informações sobre a atual pandemia, além de esclarecer a real participação de cães e gatos no ciclo de transmissão do vírus. Para isso, artigos recentes sobre o assunto foram acessados, em plataformas tais como: PubMed, SciELO e Google Acadêmico, além de livros e documentos eletrônicos, os quais foram utilizados na obtenção das informações aqui descritas, a fim de atingir não apenas a comunidade científica, mas toda a sociedade. Apesar de haver evidências de infecção por SARS-CoV-2 em cães e gatos, a transmissão do vírus por meio desses animais para os seres humanos ainda não foi confirmada. É importante também ressaltar que devido à atual situação e ao caráter dinâmico da doença, novas questões podem ser levantadas, bem como confirmações ou exclusões de hipóteses no decorrer do tempo.
\end{abstract}

Palavras-chave: Coronavírus. SARS-CoV-2. Pandemia. Quarentena.

\begin{abstract}
In the last few months, all over the world, much has been said about COVID-19, a disease that caused an outbreak in China and quickly spread around the world, becoming a pandemic. In this scenario, among several issues, a doubt was raised regarding the possibility of infection and subsequent transmission of this viral disease of pets, more specifically, dogs and cats, to individuals of the same species or even to humans. This study aims to elucidate, in a clear and objective way, what is COVID-19, its origin and the viral agent behavior responsible for the disease, in order to disseminate information about the current pandemic, in addition to clarifying the actual participation of dogs and cats in the virus transmission cycle. Recent articles were accessed, on platforms such as: PubMed, SciELO, and Google Scholar, also books and electronic documents, which were used to obtain the information described herein, in order to reach not only the scientific community, but also the society. Although there is evidence of infection with SARS-CoV-2 in dogs and cats, the virus transmission through these animals to humans has not been confirmed yet. It is also important to emphasize that, due to the current situation and its dynamic character, new questions can be raised, as well as confirmation or exclusion of hypotheses over time.
\end{abstract}

Keywords: Coronavirus. SARS-CoV-2. Pandemic. Quarantine.

\section{Introdução}

Atualmente o cenário mundial encontra-se totalmente voltado para uma nova doença causada por uma espécie de coronavírus, que se tornou assunto principal em todos os meios de comunicação. Sob o termo genérico de "coronavírus", a Coronavirus Disease - 2019 (COVID-19) tornou-se motivo de preocupação mundial após seu surgimento em dezembro de 2019, na província de Wuhan, na China.

Após casos consecutivos de uma doença aguda que levou a óbito algumas pessoas em Wuhan, pesquisadores buscaram descobrir o agente causador e rapidamente o surto foi associado a uma nova espécie de coronavírus (ZHOU et al., 2020). O agente viral recém descoberto foi primeiramente chamado de 2019-n-CoV e posteriormente denominado SARS-CoV-2 (GORBALENYA et al., 2020). A doença se espalhou rapidamente por todo o continente asiático, chegando a Europa, Américas e no mês de março foi declarada como pandemia pela Organização Mundial da Saúde (OMS) (OPAS, 2020).

Por milhares de anos espécies de coronavírus têm, eventualmente, cruzado a barreira interespécie e se tornado importantes patógenos capazes de infectar os seres humanos (CHAN et al., 2013; SU et al., 2016; WONG et al., 2016). Sabe-se, também, que em muitos lares os cães e gatos ocupam lugar de honra no âmbito familiar, sendo chamados de filhos, dormindo nas camas dos tutores e, em alguns casos, até mesmo alimentando-se à mesa com eles. Devido a esse íntimo contato e a existência de coronaviroses nestes animais, é natural que exista preocupação sobre a participação de cães e gatos no ciclo de transmissão da doença, portanto, faz-se importante esclarecer sua relação com SARS-CoV-2.

Este trabalho tem o objetivo de informar sobre a origem 
e a pandemia de COVID-19, além de elucidar questões relacionadas à participação dos cães e gatos no ciclo de transmissão da doença sob a ótica da Medicina Veterinária.

\section{Desenvolvimento}

Trata-se de um artigo técnico, com caráter informativo e científico, cujo objetivo é levar conhecimento sobre o tema não apenas dentro do meio científico, onde o acesso às informações é mais difundido, mas também para a sociedade. As informações apresentadas foram acessadas em plataformas tais como: PubMed, SciELO e Google Acadêmico, além de livros e documentos eletrônicos. Por se tratar de uma doença nova, os artigos utilizados são recentes, no entanto, livros e artigos mais antigos também foram utilizados para dar suporte teórico.

Coronavírus é um termo utilizado para se referir aos vírus que pertencem à família Coronaviridae. Esta família é dividida em duas subfamílias denominadas Letovirinae e Orthocoronavirinae, sendo que a subfamília Orthocoronavirinae é subdividida em quatro gêneros: Alphacoronavirus, Betacoronavirus, Deltacoronavirus e Gammacoronavirus (ICTV, 2019). As espécies de coronavírus que acometem os cães e os gatos pertencem ao gênero Alphacoronavirus, mais especificamente à espécie Alphacoronavirus 1, onde estão inseridos Coronavírus canino (CCoV) e Coronavírus felino (FCoV) (ICTV, 2019).

$\mathrm{CCoV}$ é um coronavírus que acomete os cães, sendo uma das causas mais comuns de gastroenterite em cães jovens, ocasionando diarreia branda e autolimitante, de caráter altamente contagioso (GREENE; DECARO, 2015). FCoV é um coronavírus que acomete os gatos e causa uma diarreia leve nos gatos infectados, entretanto, dependendo do status imunológico do animal pode ocorrer mutação in vivo do agente desencadeando a peritonite infecciosa felina, uma doença grave e debilitante que não tem cura (ADDIE; JARRET, 2006). Embora já tenha sido relatada a infecção experimental de gatos por $\mathrm{CCoV}$, sem manifestação da doença (BARLOUGH et al., 1984; McARDLE et al., 1990), é importante ressaltar que em condições naturais a transmissão interespécie não costuma ocorrer.

SARS-CoV-2 é uma espécie pertencente ao gênero Betacoronavirus que é composto, além de outras, por espécies virais que ocasionam doenças respiratórias em humanos. Duas espécies virais classificadas no gênero Betacoronavirus já foram descritas há alguns anos ocasionando doença respiratória em humanos, sendo elas: Vírus da Síndrome Respiratória Aguda Grave (SARS-CoV) e Vírus da Síndrome Respiratória do Oriente Médio (MERS-CoV) (CUI et al., 2019).

Estudos sugeriram que SARS-CoV-2 já existia, porém estava restrito a reservatórios silvestres e, possivelmente, realizou salto interespécie (YE et al., 2020). Com base em surtos anteriores, pesquisadores haviam alertado para a possibilidade de um salto interespécie de Human Coronavirus $(\mathrm{HCoV})$ presente em reservatórios silvestres como os morcegos (CHENG et al., 2007; MENACHERY et al., 2015). Contudo, é sabido que SARS-CoV-2 não emergiu de nenhum animal doméstico e não há qualquer relação entre ele e os Alphacoronavirus (WHO, 2020).

COVID-19 é uma síndrome respiratória que causa sintomas semelhantes aos apresentados pela gripe comum, porém, pode levar à ocorrência de pneumonia, que por sua vez, pode desencadear falência respiratória grave em pessoas imunocomprometidas, tais como: idosos, pessoas com comorbidades (diabéticos, pacientes em tratamento contra o câncer, hipertensos, portadores de enfermidades respiratórias crônicas, dentre outras) (ZHU et al., 2019; PERLMAN, 2020).

Após os primeiros casos de COVID-19 em Wuhan, Zhou et al. (2020) analisaram amostras de sete pacientes que apresentavam os mesmos sinais clínicos e descobriram que o agente viral causador da doença possuía $79 \%$ de identidade de nucleotídeos com SARS-CoV, responsável pelo surto ocorrido há 18 anos. O vírus recém descoberto foi então denominado temporariamente de 2019-n-CoV. A análise do genoma completo de 2019-n-CoV mostrou que as sequências nucleotídicas apresentavam menos de $80 \%$ de identidade com SARS-CoV, porém, análises das sequências de aminoácidos mostraram 94\% de similaridade com Bat-SARSr-CoV, sugerindo se tratar da mesma espécie. Entretanto, ainda comparando seu genoma completo, observou-se que SARSCoV-2 apresentava 96,2\% de identidade de nucleotídeos com coronavírus BaTCoV-RaTG13 presente em morcegos, indicando que possivelmente o morcego poderia ser o reservatório natural do novo agente viral (ZHOU et al., 2020). É também importante ressaltar que ao analisar o alinhamento das sequências de nucleotídeos do genoma completo de 2019-n-CoV, BaTCoV-RaTG13, SARS-CoV e Bat-SARSr$\mathrm{CoV}$, anteriormente relatados, não foram demonstradas evidências de recombinação entre eles no genoma do novo vírus, que foi posteriormente denominado de SARS-CoV-2 (GORBALENYA et al., 2020).

Outro estudo relatou a existência de um outro possível ancestral para SARS-CoV-2, cujo reservatório seria um pequeno mamífero chamado pangolim (Manis javanica), no entanto, o vírus presente nesta espécie compartilha 85 a $92 \%$ de identidade de nucleotídeos com o genoma completo de SARSCoV-2, indicando que possivelmente exista uma terceira espécie silvestre envolvida na transmissão, na qual possa estar presente SARS-CoV-2 ou outra espécie geneticamente mais próxima dele (HUANG et al., 2020; LAM et al., 2020).

Em 2002, no surto de SARS, estudos demonstraram ser possível infecção experimental de gatos e furões com SARSCoV. Martina et al. (2003) avaliaram a suscetibilidade dessas duas espécies ao vírus, inoculando vírus proveniente de um paciente que morreu de SARS, após quatro passagens em células Vero. O estudo concluiu que ambas as espécies eram 
suscetíveis ao vírus.

Assim como SARS-CoV, SARS-CoV-2 também utiliza o receptor para a enzima conversora de angiotensina II (ACE2) para adentrar às células dos seres humanos. Esse receptor está presente também em outras espécies animais, tais como ratos, gatos, suínos, furões, orangotangos e macacos, contudo, nos receptores ACE2 dos ratos não é possível sua ligação, devido a presença de uma histidina na posição 353. A presença desse aminoácido faz com que os receptores ACE2 dos ratos não sejam compatíveis com o receptor utilizado pelo vírus para infecção em humanos, no qual essa posição é ocupada por uma lisina (WAN et al., 2020). Li et al. (2020) avaliaram os sítios de ligação dos receptores ACE2 e descobriram três regiões, contendo de 3 a 11 aminoácidos, envolvidas na ligação do vírus. A análise das sequências mostrou que estas regiões são idênticas entre humanos e macacos, mas entre as demais espécies existem diferenças nos resíduos de aminoácidos consideradas importantes para que haja ligação do vírus nos receptores dessas espécies. Entretanto, o impacto dessas diferenças ainda é desconhecido, de forma que a possibilidade de transmissão interespécies não foi descartada (LI et al., 2020).

Até o dia 23 de abril de 2020, 30 cães e 17 gatos de famílias infectadas com COVID-19 haviam sido colocados em quarentena em Hong Kong, e desses, dois cães e um gato foram positivos por PCR quantitativo em tempo real (RT$P C R$ ) para SARS-CoV-2 (WSAVA, 2020). Além disso, os 30 cães apresentaram anticorpos anti-SARS-CoV-2 (ProMED, 2020a). Dois gatos de Nova York - EUA e um gato da Bélgica, pertencentes a tutores com COVID-19, também foram positivos por RT-PCR (ProMED, 2020b).

$O$ potencial de transmissibilidade do vírus por meio de cães e gatos infectados também foi avaliado. O primeiro caso foi de um cão da raça Lulu-da-Pomerânia, de 17 anos de idade, em quarentena em Hong Kong, positivo por realtime $P C R$, onde a análise das sequências do vírus presente no cão e em seu tutor evidenciou que houve transmissão do vírus presente no tutor para seu cão, entretanto, não foi possível o isolamento viral. O segundo caso, também em Hong Kong, foi de um cão da raça Pastor Alemão, de 2 anos de idade, positivo por real-time $P C R$, porém, neste animal o isolamento viral foi possível, contudo é importante ressaltar que, além do cão não apresentar nenhum sinal clínico, outro cão contactante não foi positivo por real-time $P C R$, indicando que não houve transmissão entre eles (WSAVA, 2020).

Devido aos casos relatados e à necessidade de maiores investigações sobre a infecção e transmissão de SARS-CoV-2 em cães e gatos, IDEXX Laboratories Inc. avaliou mais de 4000 amostras dessas espécies durante a validação de um novo sistema de teste médico veterinário para a COVID-19 e todas as amostras foram negativas. Os pesquisadores responsáveis recomendaram que não sejam feitos testes para COVID-19 nestes animais e se estes apresentarem quaisquer sinais respiratórios devem ser levados a um médico veterinário, a fim de que sejam submetidos a exames para doenças respiratórias comuns na clínica médica de pequenos animais (IDEXX Laboratories Inc., 2020). É importante ressaltar que a recomendação da OMS é que não se utilize os testes para diagnóstico de COVID-19 em animais, além disso, ressaltase que pessoas infectadas ou suspeitas, por segurança, devem evitar contato com seus pets (OPAS, 2020).

Embora ainda não haja confirmações científicas sobre a sobrevivência de SARS-CoV-2 sobre a pele ou pelo dos animais, existe a possibilidade de que tanto cães quanto gatos ou outros animais de companhia possam atuar como fômites, sendo carreadores mecânicos do vírus (HOSIE et al., 2020). Desta forma, deve-se, se possível, manter esses animais distantes de pessoas sabidamente infectadas com COVID-19.

\section{Conclusão}

A cada dia certamente aparecerão mais notícias sobre a origem e espécies animais envolvidas na transmissão da COVID-19. Diante disso, é imprescindível buscar informações atualizadas em fontes confiáveis. Até o momento, embora alguns cães e gatos tenham sido positivos para SARSCoV-2, não existem casos confirmados de transmissão entre estas espécies animais e os seres humanos. Desta forma, a recomendação é que pessoas com sintomas fiquem isoladas e evitem contato com seus pets, para evitar uma possível participação deles no ciclo de transmissão. Além disso, é importante que os cães e gatos fiquem em suas casas, evitando que tenham contato com pessoas infectadas e, que desta forma, possam agir como fômites, carreando o agente viral e possibilitando a infecção de seus tutores.

\section{Referências}

ADDIE, D.D.; JARRETT, O. Feline Coronavirus Infections. In: GREENE, C.E. Infectious diseases of the dog and the cat. St. Louis: Saunders Elsevier, 2006. p.88-102.

BARLOUGH, J.E. et al. Experimental inoculation of cats with canine coronavirus and subsequent challenge with feline infectious peritonitis virus. Laboratory Anim. Scie., v.34, n.6, p.592-597, 1984.

CHAN, J.F. et al. Interspecies transmission and emergence of novel viruses: lessons from bats and birds. Trends Microbiol., v.21, p.544-555, 2013. doi: 10.1016/j.tim.2013.05.005

CHENG, V.C. et al. Severe acute respiratory syndrome coronavirus as an agent of emerging and reemerging infection. Clin. Microbiol. Revi., v.20, n.4, p.660-694, 2007. doi: 10.1128/ CMR.00023-07

CUI, J. et al. Origin and evolution of pathogenic coronaviruses. Nat. Rev. Microbiol., v.17, p.181-192, 2019. doi: 10.1038/s41579018-0118-9

GORBALENYA, A.E. et al. The species severe acute respiratory syndrome-related coronavirus: classifying 2019-nCoV and naming it SARS-CoV-2. Nat. Microbiol., v.5, p.536-544, 2020. doi: 10.1038/s41564-020-0695-Z

GREENE, C.E.; DECARO, N. Canine viral enteritis. In: GREENE, C.E. Doenças infecciosas em cães e gatos. Guanabara Koogan: Rio de Janeiro, 2015. p.179-186. 
IDEXX Laboratories Inc. Leading Veterinary Diagnostic Company Sees No COVID-19 Cases in Pets. Disponível em: $<$ https://www.idexx.com/en/about-idexx/news/no-covid-19cases-pets/?fbclid=IwAR0Dp1yAqdiRQ9jqDr0FsTJSD3Q1PT7 LwhhbQQHkEQMdARYdJ8dekYogw9Y>. Acesso em: 27 mar. 2020.

HOSIE, M.J. et al. SARS-Coronavirus (CoV)-2 and cats. Disponível em: <http://www.abcdcatsvets.org/sars-coronavirus2-and-cats/>. Acesso em: 17 maio 2020.

HUANG, C. et al. Clinical features of patients infected with 2019 novel coronavirus in Wuhan, China. The Lancet, v.395, n.10223, p.497-506, 2020. doi: 10.1016/S0140-6736(20)30183-5

ICTV - International Committee on Taxonomy of Viruses. Master Species List (MSL34) - Update. 2019. Disponível em: <https:// talk.ictvonline.org/files/master-species-lists $/ \mathrm{m} / \mathrm{msl} / 8266>$. Acesso em: 25 mar. 2020.

LAM, T. et al. Identification of 2019-nCoV related coronaviruses in Malayan pangolins in southern China. Nature, 2020. doi: 10.1038/s41586-020-2169-0

LI, R. et al. Analysis of angiotensin-converting enzyme 2 (ACE2) from different species sheds some light on cross-species receptor usage of a novel coronavirus 2019-nCoV. J. Infec., v.80, n.4, p.469-496, 2020. doi: 10.1016/j.jinf.2020.02.013

MARTINA, B.E.E. et al. SARS virus infection of cats and ferrets. Nature, v.425, n.6961, p.915-915, 2003. doi: 10.1038/425915a

McARDLE, F. et al. Canine coronavirus infection in cats; a possible role in feline infectious peritonitis. In: CAVANAGH, D.; BROWN, T.D.K. Coronaviruses and their diseases. Plenum Press, New York, 1990. p.475-479. doi: 10.1007/978-1-46845823-7_66

MENACHERY, V.D. et al. SARS-like cluster of circulating bat coronaviruses shows potential for human emergence. Nature Medicine, v.21, n.12, p.1508, 2015. doi: 10.1038/nm.3985

OPAS - Organização Pan-Americana da Saúde. Folha informativa - COVID-19 (doença causada pelo novo coronavírus). Disponível em: $<$ https://www.paho.org/bra/index.php?option=com content $\&$ view $=$ article $\&$ id $=6101$ : covid $19 \&$ Itemid $=875>$. Acesso em: 6 abr. 2020.

PERLMAN, S. Another decade, another Coronavirus. New England J. Med., v.382, p.760-762, 2020. doi: 10.1056/ NEJMe2001126
Program for Monitoring Emerging Diseases (ProMED): COVID-19 update (56): China (Hong Kong) animal, dog, final serology positive, 2020a. Ed. International Society for Infectious Diseases. Disponível em: <https://www.tephinet.org/promedoutbreak-alerts $>$. Acesso em: 17 mar. 2020

Program for Monitoring Emerging Diseases (ProMED): PRO/ AH/EDR > COVID-19 update (123): USA (NY) animal, cat, 2020b: 20200422.7256272. Disponível em: <https://www.aphis. usda.gov/aphis/newsroom/news/sa_by_date/sa-2020/sars-cov-2animals $>$. Acesso em: 17 mar. 2020.

$\mathrm{SU}$, S. et al. Epidemiology, genetic recombination, and pathogenesis of coronaviruses. Trends in Microbiology, v.24, p.490-502, 2016. doi: 10.1016/j.tim.2016.03.003

WAN, Y. et al. Receptor recognition by the novel coronavirus from Wuhan: an analysis based on decade-long structural studies of SARS coronavirus. J. Virol., v.94, n.7, p.e00127-20, 2020. doi: 10.1128/JVI.00127-20

WHO - World Health Organization. Director-General's opening remarks at the media briefing on COVID-19-11 March 2020. Disponível em: <https://www.who.int/dg/speeches/detail/whodirector-general-s-opening-remarks-at-the-media-briefing-oncovid-19---11-march-2020>. Acesso em: 18 mar. 2020.

WONG, L.Y. et al. A molecular arms race between host innate antiviral response and emerging human coronaviruses. Virol. Sinica, v.31, n.1, p.12-23, 2016. doi: 10.1007/s12250-015-3683-3

GLOBAL VETERINARY COMMUNITY (WSAVA). ADVISORY DOCUMENT: UPDATED AS OF MARCH 20, 2020. COVID-19 and Companion Animals - What we know today. Disponível em: <https://wsava.org/wp-content/uploads/2020/04/ COVID-19-and-Companion-Animals-What-we-know-today. pdf>. Acesso em: 17 mai. 2020.

YE, Z.W. et al. Zoonotic origins of human coronaviruses. Int. J. Biol. Scie., v.16, n.10, p.1686-1697, 2020. doi: 10.7150/ ijbs. 45472

ZHOU, P. et al. A pneumonia outbreak associated with a new coronavirus of probable bat origin. Nature, v.579, p.270-273, 2020. doi: $10.1038 / \mathrm{s} 41586-020-2012-7$

ZHU, N. et al. A novel coronavirus from patients with pneumonia in China, 2019. New England J. Med.|, v.382, p.727-733, 2020. doi: 10.1056/NEJMoa2001017. 